\title{
CHORANGIOMA- A RARE CAUSE FOR POLYHYDRAMNIOS AND FOETAL DISTRESS
}

\author{
Rigith Babu Paul1, Ashima², Roma Isaacs ${ }^{3}$
}

1Postgraduate Resident, Department of Pathology, Christian Medical College and Hospital, Ludhiana.

${ }^{2}$ Assistant Professor, Department of Pathology, Christian Medical College and Hospital, Ludhiana.

3 Professor, Department of Pathology, Christian Medical College and Hospital, Ludhiana.

HOW TO CITE THIS ARTICLE: Paul RB, Ashima, Isaacs R. Chorangioma- a rare cause for polyhydramnios and foetal distress. J. Evolution Med. Dent. Sci. 2018;7(07):939-941, DOI: 10.14260/jemds/2018/214

\section{PRESENTATION OF CASE}

The following case report is of a female patient, $\mathrm{G}_{2} \mathrm{P}_{1} \mathrm{~L}_{1}$ with gestational diabetes mellitus, polyhydramnios and foetal distress. She was taken up for caesarean section and delivered a neonate with no anomalies. Placenta was enlarged and showed a large nodule on foetal surface.

Differential diagnoses were placental lesions like placental teratoma, incomplete or partial hydatidiform mole, haematoma, villous capillary lesions and chorangioma.1,2,3

The placenta delivered was sent for histopathological examination (HPE) with clinical diagnosis of chorangioma.

On gross inspection, the placenta measured $15 \times 11 \times 6 \mathrm{cms}$ along with a large, soft to firm, solitary, well circumscribed, bulging, ovoid, nodular mass measuring $11.5 \times 7 \times 6 \mathrm{cms}$, superficial to the placental disc on the foetal surface and weighing 982 gms (Figure-I). The attached umbilical cord measured $14 \mathrm{~cm}$ in length and was eccentrically inserted 6 $\mathrm{cm}$ from nearest margin. The placenta had complete membranes and maternal surface showed complete cotyledons. Serial cut sections through the placenta showed small areas of infarction and the mass showed soft, greyish brown to dark, red-tan solid areas along with greyish-white necrotic areas (Figure-II).

Microscopy of the nodular mass showed a tumour well demarcated from the surrounding placental parenchyma located under the chorionic plate. The tumour was comprised of abundant vascular channels- mainly small capillary sized, closely placed congested vessels lined by bland endothelium. Few vessels were large sized and showed intravascular thrombi. The stroma surrounding the capillaries was inconspicuous, loose, showed focal hyalinisation, myxoid change and areas of haemorrhagic necrosis. Mitosis and atypia were insignificant (Figure-III). Histopathological examination of the placenta showed small sized terminal villi with focal crowding, abundant intervillous fibrinous exudates and spotty areas of coagulative necrosis indicating placental infarction. The membranes showed oedema, while the umbilical cord showed two arteries and one vein with arterialisation of vein.

'Financial or Other Competing Interest': None.

Submission 22-12-2017, Peer Review 01-02-2018,

Acceptance 07-02-2018, Published 12-02-2018.

Corresponding Author:

Dr. Rigith Babu Paul,

Department of Pathology,

Christian Medical College and Hospital,

Brown Road, Ludhiana-141008,

Punjab.

E-mail: rigithpaul@gmail.com

DOI: $10.14260 /$ jemds $/ 2018 / 214$

\section{(c) (i) $\$$}

\section{PATHOLOGICAL DISCUSSION}

Placental neoplastic diseases are classified as trophoblastic and non-trophoblastic diseases (NTD). ${ }^{4}$ NTD are common, of which chorangioma is the most common benign growth of placenta characterised by abnormal vascular development. ${ }^{4}$ Chorangioma, first described by John Clarke in $1798^{5}$ occurs in $0.5 \%-1 \%$ of all placentas. $1,4,6,7$ It usually arises as a single tumour, but less commonly as multiple nodules arising from chorionic tissue of placenta in the third trimester of pregnancy.1,6,7 Most are less than $5 \mathrm{~cm}$, have no clinical importance and do not complicate pregnancy.1,2,7 Large sized chorangiomas are associated with varied complications in the form of polyhydramnios and intrauterine foetal hypoxia, $1,7,8$ as also seen in our case.

The placenta in our patient also showed a single, large, discrete nodule, well demarcated from the adjoining placental parenchyma.

Based on Histological Features, Chorangioma is classified by Marchetti into Three Types ${ }^{9}$

1. Cellular Type: Immature and contains mostly cellular elements packed compactly.

2. Angiomatous Type: Most common type. It is distinguished by the presence of numerous small blood vessels.

3. Degenerative Type: Mature type with degenerative changes like calcification, necrosis and hyalinisation.

Chorangioma has a benign nature with no malignant potential. ${ }^{4}$ If the mitotic count is more than 7 per 10 highpower fields, associated with cytologic atypia and necrosis, it is termed as atypical chorangioma. 10

The differential diagnosis of lesions like placental teratoma, incomplete or partial hydatidiform mole and nonvascular lesions- haematoma can be easily confirmed by HPE. $1,2,3$

Other villous capillary lesions include chorangiosis, chorangiomatosis and chorangiocarcinoma. ${ }^{2,3}$

Chorangiosis consists of diffuse increase in number of vascular channels per villus, more than 10 capillaries, in at least 10 terminal villi, in 3 low-power fields of placenta. $2,3,11$ Chorangiomatosis does not form discrete masses or have thick walled vessels unlike chorangioma.2,3 Chorangiocarcinoma comprises of chorangioma with trophoblastic proliferation and marked atypia. ${ }^{2,3}$

Uterine lesions such as submucosal or degenerated leiomyoma due to its close proximity to the uterine cavity can be confused with chorangioma clinically and confirmed by HPE. 12,13 


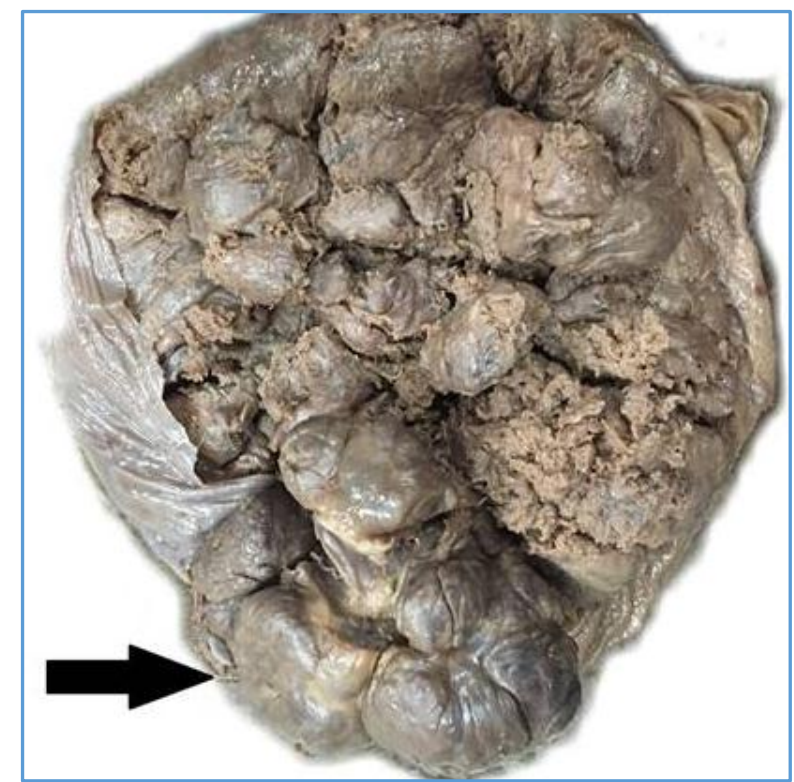

Figure 1. Placenta measured 15 x 11 x $6 \mathrm{cms}$ along with a Large, Soft to Firm, Solitary, Well Circumscribed, Bulging, Ovoid, Nodular Mass measuring 11.5 × 7 × $6 \mathrm{cms}$

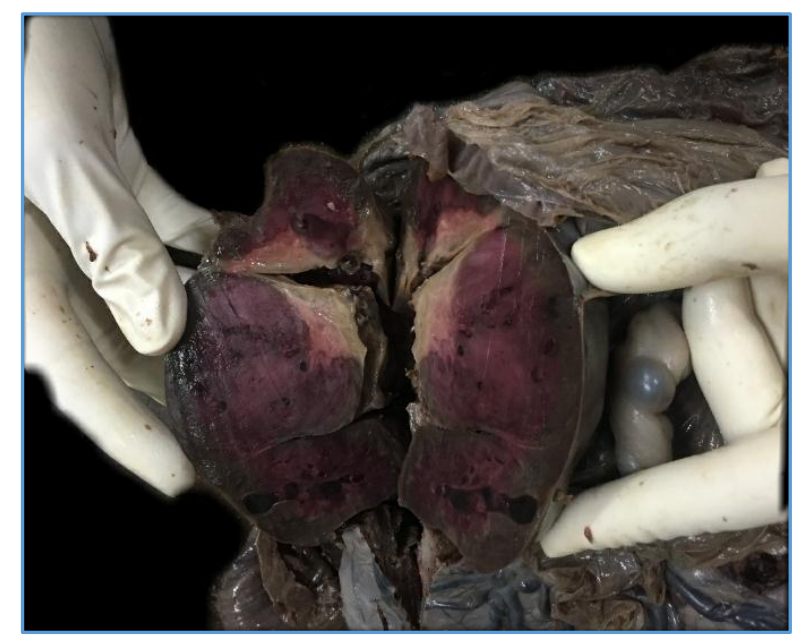

Figure 2. Cut Section through the Mass showed Soft, Greyish Brown to Dark, Red-Tan Solid Areas along with Greyish White Necrotic Areas

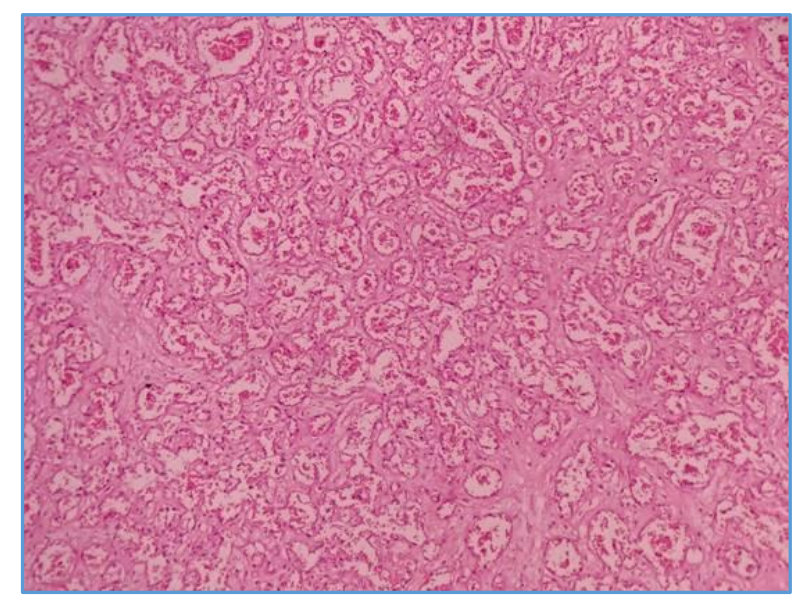

Figure 3. [H and E- 100X]: Abundant Small Capillary Sized, closely placed Congested Vessels Lined by Bland

Endothelium. The Stroma surrounding the Capillaries was Inconspicuous and Loose. Mitosis and Atypia were Insignificant

\section{DISCUSSION OF MANAGEMENT}

Large sized chorangiomas give rise to maternal, foetal and neonatal complications. $1,2,7,8,14$ The maternal complications are polyhydramnios, preeclampsia, antepartum haemorrhage, postpartum haemorrhage, premature rupture of membrane and obstructed labour.2,14

Chorangioma should be considered as a cause for such conditions. Polyhydramnios is treated with amniocentesis and maternal indomethacin therapy. 2,14

The foetal complications can range from mild-to-severe anaemia, thrombocytopenia, cardiomegaly, hepatomegaly, disseminated intravascular coagulation, hydrops foetalis, growth retardation and various other congenital anomalies. ${ }^{1,7,8,14}$

Our patient also presented with polyhydramnios and foetal distress, so was delivered promptly by caesarean section.

The placental complications are circumvallate placenta, velamentous insertion of cord, placenta previa and abruptio placenta. ${ }^{1,4,7,14}$ The placenta in this case showed eccentric cord insertion.

The interventions performed when chorangioma is diagnosed in-utero by sonography are foetal transfusions, foetoscopic laser coagulation of vessels supplying the tumour, chemosclerosis with absolute alcohol and endoscopic surgical devascularisation.4,14 Acceleration of foetal lung maturity is brought about by steroid administration. ${ }^{4,14}$

The final diagnosis was a large sized chorangioma associated with pregnancy disorder and foetal distress, however, unrelated with neonatal anomaly.

A close antenatal surveillance is warranted for early diagnosis to prevent complications, carry out appropriate intervention and timely delivery.

\section{REFERENCES}

[1] Passalacqua G, Donati L, Ferretti M, et al. Cellular placental chorangioma and adverse fetal outcome. J Clin Gynecol \& Obstet 2014;3(2):73-5.

[2] Kataria N, Singh A, Bedi PK. Giant placental chorangioma: a rare case report. J Clin Diagn Res 2016;10(4):ED03-4.

[3] Ogino S, Redline RW. Villous capillary lesions of the placenta: distinctions between chorangioma, chorangiomatosis and chorangiosis. Hum Pathol 2000;31(8):945-54.

[4] Abdalla N, Bachanek M, Trojanowski S, et al. Placental tumor (chorangioma) as a cause of polyhydramnios: a case report. Int J Womens Health 2014;6:955-9.

[5] Jaffe R, Siegal A, Rat L, et al. Placental chorioangiomatosis- a high risk pregnancy. Postgrad Med J 1985;61(715):453-5.

[6] Gersell DJ, Kraus FT. Diseases of placenta. In: Kurman RJ, Ellenson LH, Brigitte MR. eds. Blausteins pathology of the female genital tract. New York: Springer 2001: p. 1000-69.

[7] Tan SA, Yeo SH. Placental chorangioma: a case report and review. Singapore Med J 1992;33(1):83-5.

[8] Laddad MM, Patil S, Bhosale R, et al. Rare case of chorangioma of placenta. Jemds 2013;2(12):1862-7.

[9] Marchetti AA. A consideration of certain types of benign tumors of the placenta. Surg Gynecol Obstet 1939;68:733-43. 
[10] Gruca-Stryjak K, Ropacka-Lesiak M, Breborowicz GH. Nontrophoblastic placental tumors. Archives of Perinatal Medicine 2011;17(2):113-17.

[11] Zanardini C, Papageorghiou A, Bhide A, et al. Giant placental chorioangioma: natural history and pregnancy outcome. Ultrasound Obstet Gynecol 2010;35(3):332-6.

[12] Abdalla N, Piórkowski R, Stanirowski P, et al. Can ultrasound be helpful in selecting optimal management methods for pregnancies complicated by placental non-trophpblastic tumors? J Ultrason 2017;17(69):116-22.
[13] Murtoniemi K, Pirinen E, Kähkönen M, et al. Smooth muscle tumor of the placenta - an entrapped maternal leiomyoma: a case report. J Med Case Reports 2009;3:7302.

[14] Kodandapani S, Shreshta A, Ramkumar V, et al. Chorangioma of placenta: a rare placental cause for adverse fetal outcome. Article ID 913878, Case Rep Obstet Gynecol 2012;2012:1-3. 